\title{
The Role of Pharmacist in Treatment of Depression
}

\author{
Z. Binakaj ${ }^{1}$, S. Stojkov ${ }^{2}$, B. Angelovska ${ }^{3,4}$ and E. Drakalska ${ }^{4}$ \\ 1. Pharmaceutical Chamber of Federation of Bosnia and Herzegovina, Tuzlanska bb, Sarajevo 71000, Bosnia and Herzegovina \\ 2. Pharmaceutical Chamber of Serbia, Mutapova 25, Belgrade 11000, Serbia \\ 3. Pharmaceutical Chamber of Macedonia, 50 Divizija 34, Skopje 1000, Macedonia \\ 4. Faculty of Medical Sciences, University “Goce Delcev”-Stip, Stip 2000, R. Macedonia
}

\begin{abstract}
One of the most significant health issues is the disorders of mood according to the fact that they have a significant effect on the quality of life of the patients, their families, their working and wider social surroundings. According to the World Health Organization, mood disorders are the fourth cause of morbidity and mortality with a tendency to move to the second place by the 2020. The prediction of higher number of patients diagnosed with depression in the future comes from the facts that the main factor of risk, like stress, is in constant rise. Furthermore, the demographic image (ageing of the population) is changing, associated with the effect of comorbidity of depression, also attributed with increase of the number of genetically predisposed patients with this mood disorder. The aim of this study is to define, describe and question the role of pharmacists in the treatment of patients suffering from depression. Therefore, we measured the impact of pharmaceutical care on significant parameters in treatment of depression due to the selection of appropriate therapy according to the guidelines, adherence of the patient, quality of life, work capability, anxiety, side effects and interactions with other medicines.
\end{abstract}

Key words: Depression, patients, risk, stress.

\section{Introduction}

One of the most significant health issues is the disorders of mood according to the fact that they have a significant effect on the quality of life of the patients, their families, their working and wider social surroundings. According to the World Health Organization, mood disorders are the fourth cause of morbidity and mortality with a tendency to move to the second place by the 2020 [1, 2]. The prediction of higher number of patients diagnosed with depression in the future comes from the facts that the main factor of risk, like stress, is in constant rise. Furthermore, the demographic image (ageing of the population) is changing, associated with the effect of comorbidity of depression, also attributed with increase of the number of genetically predisposed patients with this mood disorder.

Over 300 million people suffer from depression

Corresponding author: B. Angelovska, Ph.D., research fields: pharmaceutical technology and social pharmacy. globally. Depression was estimated to have its highest prevalence in high-income countries attributed with great and sudden social, economic and political changes accompanied by a weakening of social support [3, 4]. Poorer socio-economic and educational status and life in urban areas are the most frequent factors for development of these disorders [5]. Studies done in the Balkans showed that an additional problem is the fact that depression is most frequently unrecognized and therefore inadequately treated [6]. Many clinical studies confirmed that depression was significantly associated with female sex [7]. Therefore, this fact is associated with negative effects on family development and functioning, the role as a parent, and with the appearance of significant disorders in children [8, 9]. Comorbidity of depression with other disorders significantly deteriorates the somatic state of the patient $[10,11]$.

The inability of administration of prescribed therapy in patients with diagnosed depression is often attributed with cessation/disruption of therapy and 
inadequate treatment of depression. This consequently leads to frequent hospitalizations, incapability to work, marginalization, and stigmatization, by the community. Therefore, this is a frequent reason for suicides by patients suffering from depression [12]. The contribution of pharmacists in treatment of depression as experts in pharmacotherapy is huge. Pharmacists through an interdisciplinary approach and appliance of pharmaceutical care can affect the proper selection of therapy by monitoring the patient's dosage regimens and detection of side effects associated with predisposition of depressive symptoms [13]. Keeping track of compliance and concordance in use of the medication for treatment of depression is of special importance. The development of pharmaceutical research studies, increase of pharmaceutical industry as well as the changes in healthcare systems and policies set additional challenges, which include continuous monitoring of the needs of patients as well as the trade and consumption of medications for the sake of rational medication administration.

\section{Materials and Methods}

The study is a randomised controlled clinical study in which a psychiatrist in General Hospital Tesanj will randomise patients according to the methods of random selection and the criteria of inclusion and exclusion defined in the protocol. The target population is adult patients 18 to 75 years old who suffer from diagnosed depressive episodes (according to the criteria set up for the diagnosis) and who are treated in General Hospital Tesanj (Bosnia and Herzegovina). A pharmacist will set up monthly appointments for the patients and educate them about depression and medications with a special review of side effects and interactions of medications. During this study, the pharmacist and the doctor will have two meetings where they will analyze observations of the pharmacist and evaluate the impact of pharmaceutical care with the intervention group. The standard group will only fill in the questionnaire about quality of life during their regular visit to the doctor at the beginning of the study, after three months and after six months of the study. For the purpose, we used the Patient Health Questionnaire (PHQ-9) which is a multipurpose instrument for screening, diagnosing, monitoring and measuring the severity of depression, modified for the needs of the hospital. Obtained results were verified by mental health professional, analyzed with SPSS software for statistical analysis of data and will include qualitative and quantitative elements.

\section{Results and Discussion}

Forty eight patients were monitored in this research, 11 men and 37 women. We noticed that the incidence of depression is more frequent in women which is also presented in the research of WHO. During this research, three tests were conducted. The obtained data showed the significance of a pharmacist in the treatment of patients suffering from depression. Consideration of the anxiety test showed that the treatment with a team which includes a pharmacist compared to a team without a pharmacist presents progress in the treatment represented by a significant decrease in irritability and anxiety. And 56\% of the patients had these symptoms during the first visit while this figure in the third visit was $4.3 \%$. Results are presented on Fig. 1.

When considering the questions from the life quality test we did not get significant results which showed us progress in the patient's depression treatment with the presence of a pharmacist in an interdisciplinary team. Also, the patients' life test showed important contribution of the pharmacists in the treatment of patients with depression.

According to the obtained results, pharmacist should be included in the interdisciplinary team, which takes care of the treatment of patients with depression, and by further education of the pharmacist in the area of mental disorders, especially depression, even better results would be achieved. A research conducted in Belgium about the role of pharmacists in care of patients with depression showed that pharmacists 


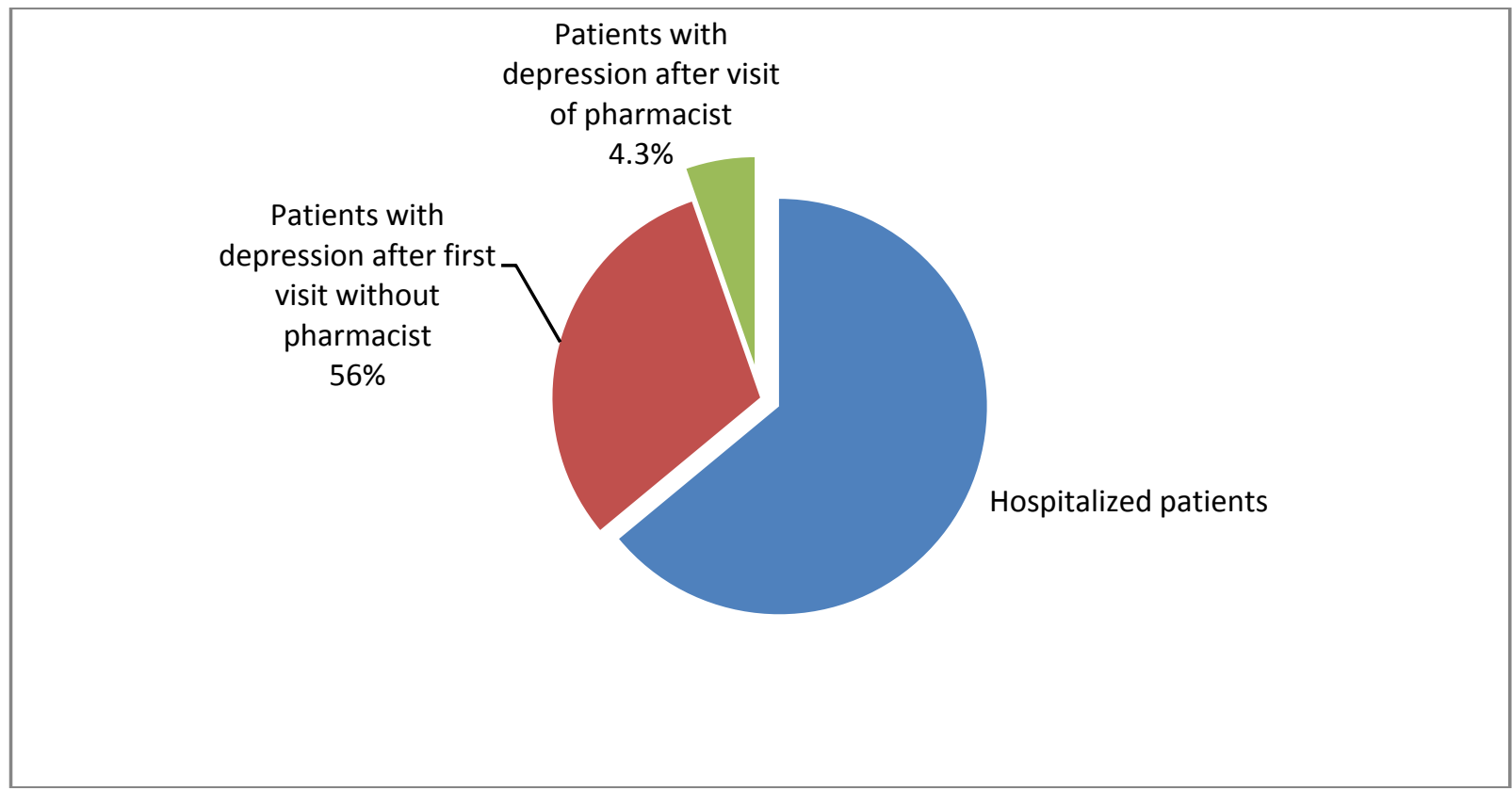

Fig. 1 Significance of a pharmacist in the treatment of patients suffering from depression.

are not sufficiently involved in the treatment of this group patients attributed with insufficient education of the pharmacists regarding mental disorders [14].

\section{Conclusions}

Pharmacists are the most devoted health professionals. Patients visit pharmacists seven times more than they visit doctors. Pharmacists, as health professionals, could improve treatment outcomes by monitoring patients about side effects, effectiveness and by providing educational information about antidepressants. These data showed us that pharmacists through pharmaceutical care can make the fastest and the cheapest contribution to a good outcome of this multidisciplinary approach in the treatment of patients with depression. Unfortunately, lack of education about psychiatric disorders, minimal time for personalized care for patients and limited private spaces in the pharmacy to talk to patients about mental health issues are most common barriers for pharmacist in primary care for patients with depression.

\section{References}

[1] World Health Organization ICD 10 Chapter V (F) Mental and Behavioral Disorders, Clinical Descriptinos and Diagnsotic Guidelines. 1992. Geneva: WHO.

[2] World Health Organization Innovative Care for Chronic Conditions: Building Blocks for Action. 2002. Geneva: WHO.

[3] Mayberry, L. J., Horowitz, J. A., and Declercq, E. 2007. "Depression Symptom Prevalence and Demographic Risk Factors among U.S. Women during the First 2 Years Postpartum.” J. Obstet Gynecol Neonatal Nurs. 36 (6): 542-9.

[4] Vaingankar, J. A., Subramaniam, M., Abdin, E. et al. 2013. "Socio-demographic Correlates of Positive Mental Health and Differences by Depression and Anxiety in an Asian Community Sample.” Ann Acad. Med. Singapore. 42 (10): 514-23.

[5] Ostler, K., Thompson, C., Kinmonth, A. L. K., et al. 2001. "Influence of Socioeconomic Deprivation on the Prevalence and Outcome of Depression in Primary Care: the Hampshire Depression Project.” Br. J. Psychiatry. 178: $12-7$.

[6] Lisulov, R., and Nedic, A. 2006. The Diagnostic and Treatment Problems in Depressive Disorders in the Primary Health Care Institutions in AP Vojvodini. Novi Sad: University of Novi Sad, Medical Faculty. 
[7] Patel, V., Todd, C. H., Winston, M., Gwanzura F., Simunyu, E., Acuda, W., et al. 1997. Common Mental Disorders in Primary Care in Harare, Zimbabwe: Associations and Risk Factors. Br. J. Psychol. 171: 60-4.

[8] Waraich, P., Goldner, E. M., Somers, J. M., et al. 2004. "Prevalence and Incidence Studies of Mood Disorders: A Systematic Review of the Literature." Can J. Psychiatry 49: 124-38.

[9] Ramchandani, P., and Stein, A. 2003. "The Impact of Parental Psychiatric Disorder on Children.” BMJ 327 (7409): 242-3.

[10] Moussavi, S., Chatterji, S., Verdes, E., Tandon, A., Pate, L. V., and Ustun, B. 2007. "Depression, Chronic Diseases, and Decrements in Health: Results from the World Health Surveys.” Lancet 370: 851-8.
[11] Kessler, R. C., Chiu, W. T., Demler, O., Merikangas, K. R., and Walters, E. E. 2005. "Prevalence, Severity, and Comorbidity of 12-Month DSM-IV Disorders in the National Comorbidity Survey Replication.” Arch. Gen. Psychiatry 62: 617-27.

[12] Bostwick, J. M., and Pankratz, V. S. 2000. "Affective Disorders and Suicide Risk: A Reexamination.” Am. J. Psychiatry 157 (12): 1925-32.

[13] Binakaj, Z. 2015. "Pharmaceutical Care with Patients Suffering from Depression.” Master's thesis, Faculty of Pharmacy, Tuzla.

[14] Liekens, S., Smits, T., Laekeman, G., and Foulon, V. 2012. "Pharmaceutical Care for People with Depression: Belgian Pharmacists' Attitudes and Perceived Barriers.” Int. J. Clin. Pharm. 34 (3): 452-9. doi: 10.1007/s11096-012-9628-0. 